\title{
EFFECT OF RELATIONSHIP STATUS ON PERCEPTIONS OF PHYSICAL ATTRACTIVENESS FOR ALTERNATIVE PARTNERS
}

\begin{abstract}
A thesis presented to the faculty of the Graduate School of Western Carolina University in partial fulfillment of the requirements for the degree of Master of Arts in Experimental Psychology.
\end{abstract}

\section{By}

Whitney Elyse Petit

Director: Dr. Thomas E. Ford

Professor

Psychology Department

Committee Members: Dr. Winford Gordon, Psychology

Dr. Erin Myers, Psychology

April 2014 


\section{ACKNOWLEDGEMENTS}

I would like to express my gratitude to my supervisor, Dr. Thomas Ford, whose expertise, understanding, and patience, added considerably to my graduate experience. Dr. Thomas Ford has been an excellent mentor and has spent countless hours with me conceptualizing this research, proofreading and crafting my writing, and overall creating a practical thesis. His direction, technical support, and willingness to research a different branch of social psychology has made this a thoughtful and rewarding journey.

I would also like to thank other members of my thesis committee, Dr. Windy Gordon and Dr. Erin Myers, for their motivation and encouragement over the past two years as I moved from an idea to a completed study. A very special thanks also goes out to Dr. William Poynter who took the time out from his schedule to provide valuable eye tracker software support during the data collection process. I must also acknowledge my social psychology lab members who provided scientific debates, exchanges of knowledge, skills, and venting of frustration during this research endeavor. 


\section{TABLE OF CONTENTS}

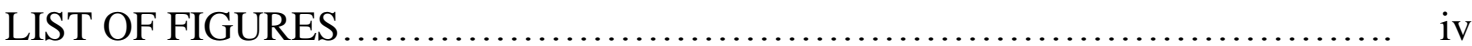

ABSTRACT ............................................................. v

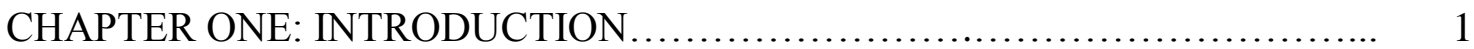

CHAPTER TWO: LITERATURE REVIEW ................................. 3

The Threat of Alternative Relationship Partners........................ 3

Explanations Underlying Devaluation of Alternative Relationship Partners.. 5

The Motivational Hypothesis......................................... 6

The Perceptual Hypothesis......................................... 8

Testing the Competing Hypotheses.................................. 9

The Present Research.................................................. 11

CHAPTER THREE: METHOD........................................... 12

Participants...................................................... 12

Procedure.......................................................... 12

CHAPTER FOUR: RESULTS............................................. 15

Self-reported Attractiveness....................................... 15

Pupil Dilation..................................................... 16

CHAPTER FIVE: DISCUSSION ........................................ 19

Motivation to Devalue Alternative Partners: The Role of Commitment..... 20

Limitations and Future Directions..................................... 21

Conclusion.......................................................... 24

REFERENCES .......................................................... 25

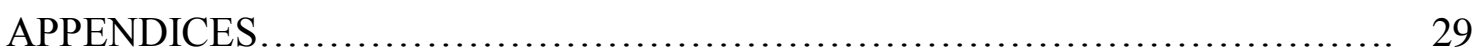

Appendix A: Consent Form...................................... 29

Appendix B: Example Filler Advertisement and Stimulus Advertisements... 31

Appendix C: Questionnaire for Filler and Stimulus Advertisements........ 33

Appendix D: Current Dating Status and Demographic Form.............. 34 


\section{LIST OF FIGURES}

Figure

Page

1 Self-reported attractiveness ratings of opposite-sex models.................. 16

2 Pupil dilation in response to opposite-sex models......................... 17

3 Goals and cognitive processes predicted to mediate the effect of relationship status on perceptions of physical attractiveness of alternative partners................................................... 23 


\author{
ABSTRACT \\ EFFECT OF RELATIONSHIP STATUS ON PERCEPTIONS OF PHYSICAL \\ ATTRACTIVENESS FOR ALTERNATIVE PARTNERS \\ Whitney Petit, M.A. \\ Western Carolina University (April 2014) \\ Director: Dr. Thomas E Ford
}

Previous research has found that as people become increasingly involved with their partners, they evaluate alternatives more negatively. The present research tested two competing hypotheses that address the origin of this mechanism: (a) the motivational hypothesis suggests that devaluing alternatives is an effortful process where attractiveness is suppressed, and (b) the perceptual hypothesis suggests that devaluation is an automatic process where those in relationships simply find alternatives less attractive (e.g., Rusbult \& Johnson, 1989; Simpson, Lerma, \& Gangestad, 1990). This study provided the first direct test of the competing hypotheses by comparing pupil dilation, an involuntary measure of attractiveness, to self-reported attractiveness ratings. People exhibited the same pupil dilation regardless of relationship status; however, coupled participants rated alternative partners as significantly less attractive compared to noncoupled participants. Taken together, these results support the motivational hypothesis in that coupled people actively suppress or recalibrate their initial automatic perceptions of attractiveness to an alternative partner as part of a relationship preservation mechanism. 


\section{CHAPTER ONE: INTRODUCTION}

"And, of course, the promise, made when I am in love and because I am in love, to be true to the beloved as long as I live, commits me to being true even if I cease to be in love."

-C. S. Lewis

In popular fairy tales characters like Snow White, Cinderella and Sleeping Beauty live happily ever after with their "Prince Charming." Unfortunately, the story is more complicated for romantic relationships in real life; couples face many obstacles and challenges to their commitment to one another, and often do not live "happily ever after." According to the 2011 U.S. Census Bureau, one out of every five marriages in the United States ends in divorce within five years of tying the knot. In 2009 the divorce rate in the United States was $3.8 \%$; that is, 38 out of every 1,000 marriages ended in divorce (U.S. Census Bureau, 2011).

The temptation of alternative partners represents a serious and pervasive threat to a couple's "happily ever after." Indeed, as many as 60 percent of men and 50 percent of women have sex with somebody other than their spouse while married (Bennett \& Ellison, 2010). Thus, understanding the mechanisms or strategies that people use to protect their relationship from this threat is a critical project for research in social psychology. Accordingly, previous research has shown that one strategy people use to protect their relationships is to devaluate the physical attractiveness of available alternative partners (Rusbult \& Johnson, 1989). This study builds upon those findings by 
providing a direct test of two competing hypotheses about the processes underlying this important relationship preservation strategy.

The present research examines perceptions of physical attractiveness, which refers to the subjective esthetic judgment of one's appearance (Byrne, London, \& Reeves, 1968). Perceiving someone as attractive represents a similar esthetic experience as how art is pretty or music sounds good. In contrast, attraction for another person is sometimes thought to imply the experience of being drawn or pulled to a person (Byrne et al., 1968). 


\section{CHAPTER TWO: LITERATURE REVIEW}

\section{The Threat of Alternative Relationship Partners}

Perhaps the first social psychological theory that addressed questions about romantic relationships was Thibaut and Kelley's (1959) Social Exchange Theory. Thibaut and Kelley suggested that all relationships involve a succession of social exchanges. How we feel about a relationship with another person depends on our perceptions of the balance between what we put into the relationship and what we get out of it, the balance of inputs and outcomes we think we deserve from a relationship, and the chances of having a better relationship with someone else.

According to Social Exchange Theory, people develop two standards, or benchmarks, to evaluate their relationships. The first standard Thibaut and Kelley called the comparison level (CL). The CL represents the balance of inputs and outcomes that a person expects from a given relationship. The CL is derived from past experiences and social comparisons with other people's relationships of a similar type. People are thought to compare relationship outcomes to an established CL to determine relationship satisfaction. When people perceive the balance of inputs and outcomes to be above the CL, they are generally satisfied with the relationship.

People also develop what Thibaut and Kelley (1959) referred to as, a comparison for alternative relationships (CLalt). The CLalt represents one's perception of the quality of the best available alternative relationship. Put another way, it is the least a person will settle for in a relationship given available alternatives. Importantly, Thibaut and Kelley proposed that as more attractive alternative possibilities become available (i.e., one's 
relationship compares unfavorably to the CLalt), the probability of relationship dissolution increases. That is, people become less committed to their relationships to the extent that there are available attractive alternatives.

Research by Rusbult (1983; Rusbult \& Johnson, 1989) empirically tested Thibaut and Kelley's (1959) suggestion about relationship commitment and attractiveness of available relationship partners. For instance, Rusbult and Johnson (1989) found that as people become more committed to their partners they evaluate available alternative relationship partners as less attractive. Rusbult and Johnson (1989) identified available alternative partners as particularly threatening to one's relationship, and found that the availability of an alternative partner moderated the degree to which "coupled" participants devaluated his or her attractiveness.

Finally, Rusbult and Johnson (1989) demonstrated that commitment to one's partner rather than satisfaction with one's relationship was responsible for coupled participants' devaluation of an alternative partner. Thus, consistent with the quote by C.S. Lewis, commitment to one's partner sets in motion mechanisms that serve to maintain a relationship even when one does not experience feelings of "being in love."

Simpson et al. (1990) expanded upon these findings by investigating how people in a committed relationship evaluate attractive others who are not available relationship partners. Participants were led to believe that they were participating in a study on the "psychology of advertising" where attractive people were imbedded in sixteen advertisements. Simpson et al. (1990) found that individuals involved in ongoing dating relationships rated opposite-sex persons featured in the advertisements as significantly less attractive than those not involved in dating relationships. This effect was reliable for 
both men and women and occurred only for young opposite-sex models (not older or same sex models), suggesting that a devaluation effect may indeed function as a mechanism of relationship maintenance. Another finding, also noteworthy, was that opposite sex persons do not have to be available relationship partners to be devalued. Pictures, which were rated for attractiveness, were of models and thus unavailable. This suggests that the devaluation of others might be a more pervasive and general mechanism of relationship maintenance than previously thought on the basis of Rusbult and Johnson's (1989) findings.

Simpson et al. (1990) found that attractive, opposite-sex individuals do not need to be available in order to be derogated. Their findings were complimentary to that of Rusbult and Johnson (1989) in that individuals involved in committed relationships tend to perceive opposite-sex persons as less physically and sexually attractive. Once involved in dating relationships, Simpson et al. (1990), suggested that individuals may possess "perceptual blinders" that effectively shield them from the distracting and tempting lure of opposite sex persons.

\section{Explanations Underlying Devaluation of Alternative Relationship Partners}

Collectively, existing research suggests that people in committed relationships devalue the attractiveness of another person, which serves as a line of defense in relationship-maintenance. Two hypotheses have been derived to account for the devaluation of alternative relationship partners; one that emphasizes a conscious motivational process and one that emphasizes an unconscious, perceptual process. According to the motivational explanation, relationship commitment motivates one to consciously override or suppress initial, automatic perceptions of attractiveness to 
another person. In other words, people convince themselves that others are less attractive. In contrast, the perceptual explanation suggests that relationship commitment inhibits the initial perceptions of attractiveness to another person directly. In other words, other people simply become less attractive.

\section{The Motivational Hypothesis}

According to the motivational hypothesis, the presence of an attractive alternative produces conflict for the committed individual and this conflict can be reduced by devaluating the attractiveness of that person (Rusbult \& Johnson, 1989). Festinger's (1957) Cognitive Dissonance Theory suggests that we have an inner drive to hold our beliefs and attitudes in harmony and avoid disharmony, or dissonance. According to Festinger (1957), we are motivated to reduce or eliminate the experience of dissonance which, in this case, would result from attractiveness to another person. Specifically, the attractiveness to another person would be dissonant with one's definition of self as a "loyal and committed partner." Commitment to partners motivates people (through the experience of cognitive dissonance) to recalibrate perceptions of attractiveness to other people so that they judge others in a way that protects their relationship and definition of self as a loyal partner. In contrast, for people not in a committed relationship, perceiving others as attractive should not produce dissonance, thus people not in a committed relationship should not devaluate the attractiveness of others.

Baumeister and Leary's (1995) Commitment Device Theory suggests that love plays an important role in preserving close relationships. Love promotes long-term bonds by acting as an internal incentive system that facilitates the maintenance of close relationships. Thus, it is the actual experience of this emotion that helps people to 
foreclose on other options. Accordingly, people induced to feel love for their partner are more successful in suppressing thoughts of alternative attractive people and refocusing attention onto their partner. To demonstrate that one is not tempted by alternatives partners, he or she forgoes gazing at others. Failure to suppress such gazes is often met with expressions like "Why were you looking at him/her?" (Gonzaga, Haselton, Smurda, Davies \& Poore, 2008).

The motivational hypothesis is consistent with other motivated cognition models, which also suggest that people consciously overrule or modify initial, automatically activated cognitions. For instance, Martin's (1986) Set/Reset Theory of construct accessibility effects proposed that contextual events can activate cognitions that bias people's impressions of others. In an effort to form an accurate impression, people consciously recalibrate their initial impression of another person by correcting for the influence of contextually activated cognitions. In addition, Crandall and Eshlemann's Justification-Suppression Model (2003) expanded on this idea of recalibration by suggesting that "genuine" prejudices are not directly expressed. Instead, people suppress prejudices according to their beliefs, values, and norms, which are restraining forces. Prejudices are expressed when justifications (e.g., attributions, ideologies, stereotypes) release suppressed prejudices.

Also, the Dual Attitude Model (Wilson, Lindsey, \& Schooler, 2000) and the Meta-Cognitive Model (Petty \& Beinol, 2007) of attitude structure each propose that people may simultaneously hold two conflicting attitudes toward an object that are stored and expressed at different levels of conscious awareness. Explicit attitudes help consciously whereas implicit attitudes exist outside of awareness. Implicit attitudes are 
thought to be automatically activated in response to the attitude object. In contrast, the expression of explicit attitudes requires the person to deliberately override the default implicit attitude and retrieve from memory the explicit attitude to bring to bear on social judgment. Conflicting attitudes, relative to devaluing alternatives, consists of an implicit attitude of attractiveness to an alternative person that is deliberately overridden by the explicit belief of being a loyal partner.

\section{The Perceptual Hypothesis}

The perceptual hypothesis emphasizes the direct effect of commitment to a relationship on perceptions of attractiveness for another person (Rusbult \& Johnson, 1989). Perhaps people in a committed relationship have a lower CLalt or less favorable evaluations of alternative romantic relationships (Thibaut \& Kelley, 1959). Given a lower perceived CLalt, people in a committed relationship are more likely to view alternative relationship partners as less attractive than those not in a committed relationship.

Supporting this logic, Kenrick and Gutierrez (1980) found evidence that an elevated CLalt can negatively affect perceptions of attractiveness of another person. Male college students rated the attractiveness of an average-looking woman before or while watching the program Charlie's Angels, which featured three very attractive, young women. Kenrick and Gutierrez (1980) found that participants rated her as less attractive while watching the program than before. Similalry, Kenrick, Gutierres, and Goldberg (1989) found that men reported being less in love with their girlfriends after looking at Playboy centerfold pictures. In addition to having a lower CLalt, people in committed 
relationships may be more adept at refocusing attention from alternative partners back to their actual partner.

The emphasis on the direct effect of motivation on perceptions is consistent with recent models in social cognition showing that motivation can affect automatic cognitive and perceptual processes that occur outside of conscious awareness and control.

Moskowitz, Wasel, Gollwitzer, and Schaal (1999) demonstrated that egalitarian motives operate outside awareness to reduce the activation of negative stereotypes about a social group. In addition, Sinclair and Kunda (1999) showed that disliking for a group increased the activation of negative group stereotypes. Relating to my research, these findings suggest that the goal to maintain a committed relationship can function to directly affect automatic, involuntary perceptions of attractiveness for an alternative person.

\section{Testing the Competing Hypotheses}

Simpson et al. (1990) found that coupled participants devalued the attractiveness of opposite sex models who were not available relationship partners. By not being available, the models presented minimal direct threat to participants' relationships. Simpson et al. (1990) suggested that because relationship threat was minimal, conscious motivational processes such as dissonance reduction should not have been triggered. Thus, Simpson et al. (1990) provided indirect support for the perceptual hypothesis.

To date, studies on the devaluation of alternative relationship partners have relied exclusively on self-report measures of attractiveness; they have not measured automatic or involuntary perceptions of attractiveness and therefore have not provided a direct test of the competing hypotheses. Research has not tested whether coupled and non-coupled 
people differ in their involuntary, automatic perceptions of attractiveness to an opposite sex person.

One automatic, perceptual measure of attractiveness is pupil dilation. Pupillometry is oftentimes obtained by the use of an eye tracker; thus, it is frequently combined with other measurements of ocular data such as eye fixation and movement. Eye movements and pupillary responses share the benefit of providing clues about the structure of cognitive processing. Pupil recording does not require overt responses and can be obtained even without participant knowledge (Laeng, Sirois \& Bredeback, 2012).

The eyes convey information about internal processes, which is why they are often referred to as "the windows to the soul." Bradley, Miccoli, Escrig, and Lang (2008) demonstrated that pupil dilation occurs very quickly and involuntarily, and it is impossible for people to suppress pupil dilation. Thus, Bradley et al. (2008) argued pupil dilation directly measures activation of the autonomic nervous system.

Hess and Polt (1960) applied pupillometry to a study of physical attractiveness. As expected, they found that the pupils of both male and female participants dilated (about $20 \%$ of the diameter compared to the baseline) when they viewed images of halfnaked members of the opposite sex. Several investigators using sexual stimuli have obtained similar findings (e.g., Nunnally, Knott, Duchnowski, \& Parker, 1967; Bernick \& Oberlander, 1968). More contemporary studies (Rieger \& Savin-Williams, 2012) also have found that people's pupils dilate in response to seeing someone who they are attracted to suggesting a direct relationship between pupil dilation and attractiveness. 


\section{The Present Research}

The present study provided the first direct of the two competing hypotheses about the mechanisms underlying the effect of relationship status on evaluations of opposite sex people. Specifically, I used the eye-tracker to measure pupil dilation while participants viewed pictures of opposite sex people to assess automatic or involuntary perceptions of attractiveness. Participants also rated the attractiveness of opposite sex people using a self-report measure.

According to the motivational hypothesis, coupled and non-coupled people should show the same level of pupil dilation in response to an opposite sex person but express a different degree of attractiveness on a self-report measure. Coupled people should censor or override their initial, automatic perceptions and report less attractiveness. In contrast, the perceptual hypothesis predicts that coupled people will actually experience less automatic, perceptual attractiveness and thus exhibit less pupil dilation in response to an opposite sex person than non-coupled people. They should also overtly express less attractiveness on a self-report measure. 


\section{CHAPTER THREE: METHOD}

\section{Participants}

A total of 72 Western Carolina University undergraduates (21 men and 51 women) participated in a study on "psychology and advertising" for partial course credit in their Introductory Psychology class. Participants were over 18 and residents of the United States. Their ages ranged from 18 to 28 with a median of $18(M=19, S D=1.45)$. Relationship status ranged from 38 coupled to 34 non-coupled participants. Sexual orientation data showed one participant to be homosexual, one bisexual, and one was classified as "other."

\section{Procedure}

Upon arrival to the neuropsychology lab, participants were greeted by a female experimenter and seated in front of an eye-tracking monitor. The experimenter informed participants that an advertising company, in cooperation with local psychologists, is interested in college students' reactions to several current advertisements. The experimenter explained some features of the eye tracker, and that the research was investigating what draws people's attention and keeps people's attention in these advertisements. Then, she told participants that they would view and rate a series of advertisements from magazines and commercials. After giving their consent (Appendix A), participants began the study.

First, participants viewed 16 advertisements from current magazines and commercials while the eye tracker collected pupil dilation data, then they viewed the same sixteen advertisements again while responding to a questionnaire. The 
advertisements were presented one at a time and the participants were in control of when they moved from viewing one advertisement to the next. Following Simpson et al. (1990) the advertisements promoted a wide array of products to support the cover story. This included advertisements for clothing, life insurance, make-up, food, and cologne/perfume to name a few. Male participants viewed the ten advertisements that featured no people - filler advertisements (included to reduce suspicion of the true purpose of the study) — plus six featuring women. Female participants viewed the same ten filler advertisements plus six featuring men. An example of a filler advertisement, an advertisement featuring a female model, and one featuring a male model can be found in Appendix B.

During the first part of data collection, the computer measured pupil dilation in response to each advertisement presented on the screen. Once this was completed, participants then viewed the advertisements again while responding to a self-report measure. For each filler advertisement participants responded to the following four items: "I like the advertisement," "The advertisement is persuasive," "The advertisement would be popular," and "The advertisement is influential." For advertisements featuring opposite-sex persons, participants also responded to two additional questions that served as a measure of physical and sexual attractiveness: "The person in the advertisement is attractive physically," and "The person in the advertisement has sex appeal." Participants responded to all items using a seven-point scale ranging from 1 (strongly disagree) to 7 (strongly agree). A copy of the questionnaires can be found in Appendix C.

Once participants evaluated the 16 advertisements on both the pupil dilation and self-report measures, they were then given a dating status and demographics form where 
they reported their current dating status and their sexual orientation (see Appendix D). If they were dating someone, they also indicated how long they have been dating their current partner. Following this, participants were thanked and debriefed. 


\section{CHAPTER FOUR: RESULTS}

\section{Self-reported Attractiveness}

The two items "The person in the advertisement is attractive physically" and "The person in the advertisement has sex appeal" were highly correlated $(r=.92)$ for the six slides featuring opposite-sex models. Therefore, I created an aggregate, global measure of self-reported attractiveness by averaging responses to the two items.

To test gender differences in perceived attractiveness for the opposite-sex models, I subjected attractiveness ratings to a one-way analysis of variance (ANOVA) with gender serving as a between subjects factor. There was no effect of gender, $F(1,72)=$ $.18, p=.67$, partial $\eta 2=.003$. Overall, men reported a similar level of attractiveness for female models $(M=5.65, S D=1.37)$ as women did for male models $(M=5.51, S D=$ 1.18).

According to both the motivational and perceptual hypotheses, coupled participants should rate the opposite-sex models as less attractive than non-coupled participants. To test this hypothesis, I subjected the attractiveness ratings to a one-way ANOVA with dating status serving as the between subject factor. The predicted main effect of dating status was significant, $F(1,70)=4.72, p=.033$, partial $\eta 2=.063$. Mean self-reported attractiveness ratings are displayed in Figure 1. As shown in Figure 1, the self-reported attractiveness ratings are consistent with both hypotheses and with previous findings (Simpson et al., 1990). Coupled participants reported significantly less attractiveness $(M=5.26, S D=1.50)$ to models in the advertisements compared to noncoupled participants $(M=5.88, S D=0.71)$. 


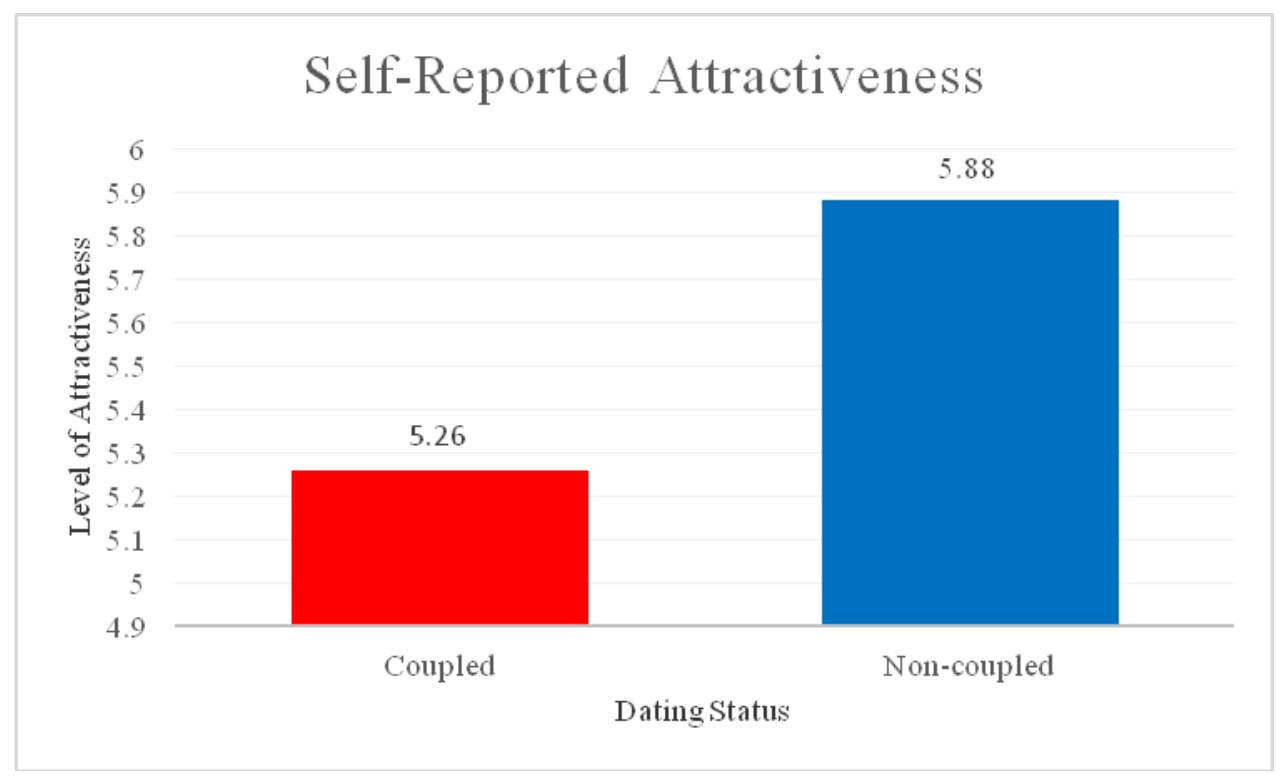

Figure 1. Self-reported attractiveness ratings of opposite-sex models.

\section{Pupil Dilation}

I computed an overall measure of pupil dilation by dividing the amount of pupil dilation in response to the stimulus advertisements by the amount of pupil dilation in response to the filler advertisements. On average, the stimulus/filler ratio was slightly above 1.0, which one would expect, given the stimulus advertisements were designed to create arousal, whereas the filler advertisements were not.

Again, to test gender differences in automatic perceptions of attractiveness for the opposite-sex models, I subjected pupil dilation to a one-way ANOVA with gender serving as a between subjects factor. There was a significant effect of gender, $F(1,70)=$ $6.60, p=.012$, partial $\eta 2=.086$. Overall, men showed less pupil dilation for female models $(M=1.01, S D=0.02)$ than women did for male models $(M=1.02, S D=0.02)$. 
According to the motivational hypothesis, coupled participants and non-coupled participants should exhibit a similar degree of pupil dilation. Conversely, the perceptual hypothesis suggests that coupled participants should have less pupil dilation than noncoupled participants. To test these hypotheses, I subjected the pupil dilation measure to a one-way ANOVA with dating status serving as the between subject factor. The main effect of dating status was not significant, $F(1,70)=.053, p=.818$, partial $\eta 2=.001$. Mean pupil dilation ratios are displayed in Figure 2. Coupled participants had similar pupil ratios $(M=1.02, S D=.02)$ compared to non-coupled participants $(M=1.02, S D=$ $.02)$.

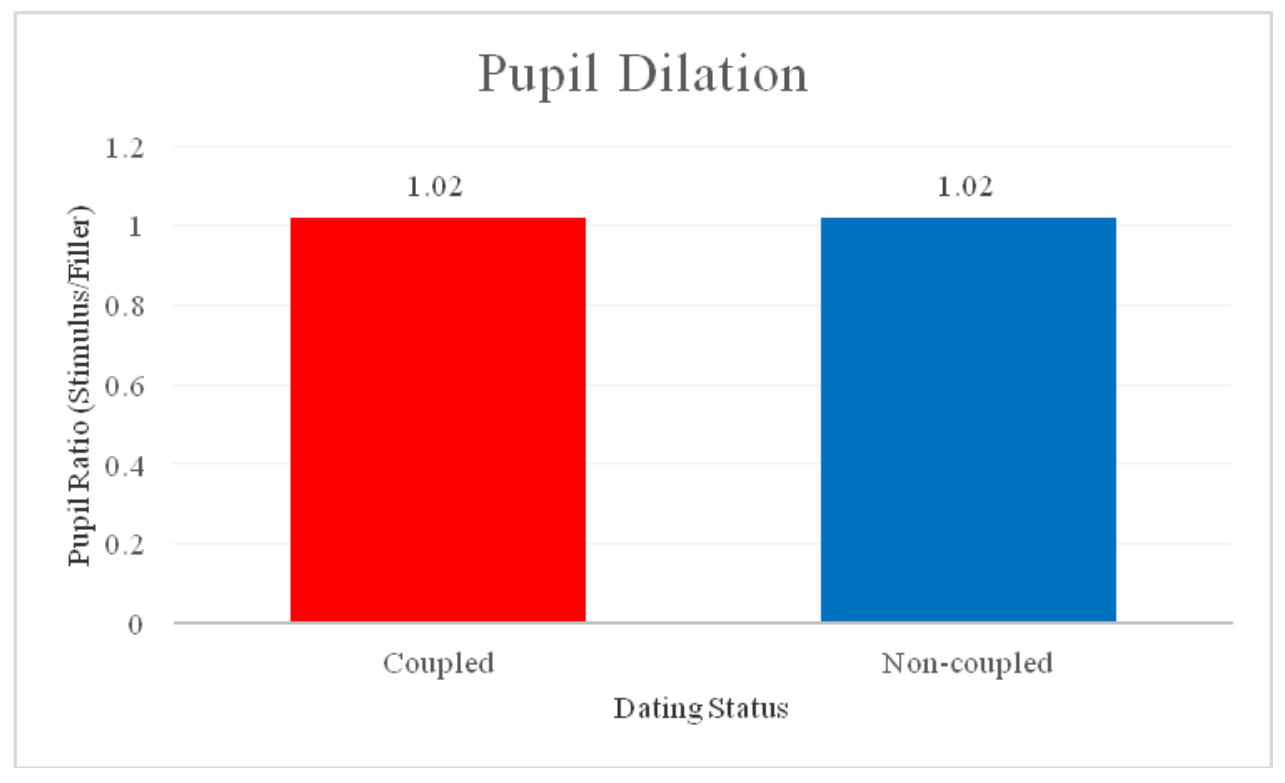

Figure 2. Pupil dilation in response to opposite-sex models.

To further test between the motivational and perceptual hypotheses, I performed a 2 dating status (coupled vs. non-coupled) x 2 measure (pupil dilation, self-report) mixed model ANOVA with measure serving as a within-subjects variable. In support of the 
motivational hypothesis, there was a significant dating status x measure interaction effect, $F(1,70)=4.74, p<.03$. The effect of dating status differed between the self-report and pupil dilation measures. There was a significant effect of dating status on self-reported attractiveness, but there was not a significant effect of dating status on pupil dilation. 


\section{CHAPTER FIVE: DISCUSSION}

Close relationships can be the source of incredible joy; but they can also be the source of profound pain. The incentives in relationships are many, including affection, laughter, intimacy, love, and companionship. The threats in relationships, however, are almost equal in number, such as conflict, rejection, competition, jealously, and grief. In short, close relationships include both potential rewards and potential punishments. Despite the seemingly precarious balance between incentives and threats in close relationships, across the life span people are nevertheless motivated to form and maintain strong and stable social bonds; failing to do so is linked with higher mortality and lower health and well-being. Not surprisingly then, people have a deep underlying desire to preserve romantic relationships (Baumeister \& Leary, 1995).

Preemptive mechanisms are behaviors or cognitive tactics that serve the function of minimizing or avoiding a threat to one's romantic relationship before it happens (Simpson et al., 2001). That is, contrary to reactionary mechanisms, which repair damage that has already occurred, preemptive mechanisms avoid the damage and navigate around potential threatening events. One threat to romantic relationships is the availability of alternative relationship partners. Previous research has shown that one important way people protect their relationships is to devaluate the attractiveness of available alternative partners (Rusbult \& Johnson, 1989). Minimizing the attractiveness of an alternative partner is similar to other preemptive tactics like the avoidance of gazing at attractive others. In both instances, people minimize or avoid the threat of an 
alternative relationship partner rather than being on damage control after the consequences have taken place.

The present research extends previous findings by providing the first direct test of two competing hypotheses about the processes underlying this important relationship preservation strategy. According to the motivational hypothesis, coupled and noncoupled people perceive alternative relationship partners as equally attractive. Coupled people however actively suppress or recalibrate initial automatic attractiveness in order to guard against the threat. In contrast, the perceptual hypothesis suggests that coupled people actually perceive alternative relationship partners as less attractive. The results of the present study support the motivational hypothesis. Both coupled and non-coupled participants exhibited an equal degree of pupil dilation in response to opposite-sex models. However, coupled participants rated the opposite-sex models as less attractive on a self-report measure. These findings suggest that both coupled and non-coupled participants perceived the models as equally attractive. Coupled participants, though, actively suppressed or recalibrated their attractiveness for the models.

\section{Motivation to Devaluate Alternative Partners: The Role of Commitment}

My findings are consistent with other research that supports the motivational nature of devaluation. Lydon, Fitzsimons, \& Naidoo (2003) found that people derogate the attractiveness of alternatives when the threat matches their level of commitment. Lydon et al. (2003) manipulated the level of threat an alternative relationship partner posed to participants' close relationships by varying the degree to which the alternative person was available and interested in dating the participant. Moderately committed participants (i.e., exclusively dating) rated an opposite-sex target as least attractive in the 
moderate threat condition (i.e., when the alternative partner was available, but expressed no interest in the participant). Highly committed participants (i.e., married) rated an opposite-sex target as least attractive in the high threat condition (i.e., when the alternative partner was available and expressed interest in the participant). When alternative partners are unambiguously better or worse than current partners, the choice is clear and dissonance is low and requires no resolution. However, when the threat matches the current relationship, the choice is not clear and dissonance is high and requires resolution. Thus, devaluation occurs as a means of protecting one's relationship from the temptation of an alternative partner (Lydon et al., 2003).

Further, as commitment to a close relationship increases motivation to engage in strategies to maintain the relationship also increases. Accordingly, Rusbult and Johnson (1989) found that people devalue the physical attractiveness of others to a greater degree when they are more committed to their relationship. To the extent that one is committed to a relationship, they experience more dissonance associated with finding someone else attractive.

\section{Limitations and Future Directions}

Although my experiment provided clear support for the motivational hypothesis, it does have limitations to be addressed in future research. Most notably, it did not examine the mechanisms by which coupled people devalue the attractiveness of alternative partners. One possibility is that coupled people actively pay less attention to the physical attractiveness of others. Koranyi and Rothermund (2012) propose that people are differentially attentive to the attractiveness of opposite-sex others depending on their relationship goals. They suggested that people can have either "relationship- 
seeking" or "relationship-maintaining" goals, which serve different functions.

Relationship-seeking goals facilitate the attainment of a new relationship, whereas relationship-maintaining goals function to protect an existing relationship.

Accordingly, relationship-seeking goals prompt people to more fully attend to and think about the attractiveness and reciprocal interest of opposite sex others. In contrast, relationship-maintaining goals reduce the attention people pay to attractiveness and reciprocal interest thus protecting an existing relationship from the threat of available alternatives. In other words, "relationship-maintainers" may recognize or acknowledge the attractiveness of others but do not dwell on it as "relationship seekers" might. From this framework, coupled participants presumably had relationship-maintaining goals making them less attentive to the attractiveness of opposite-sex models. As a result, coupled participants rated the models as less attractive than did non-coupled participants. This possibility is depicted in Figure 3. 


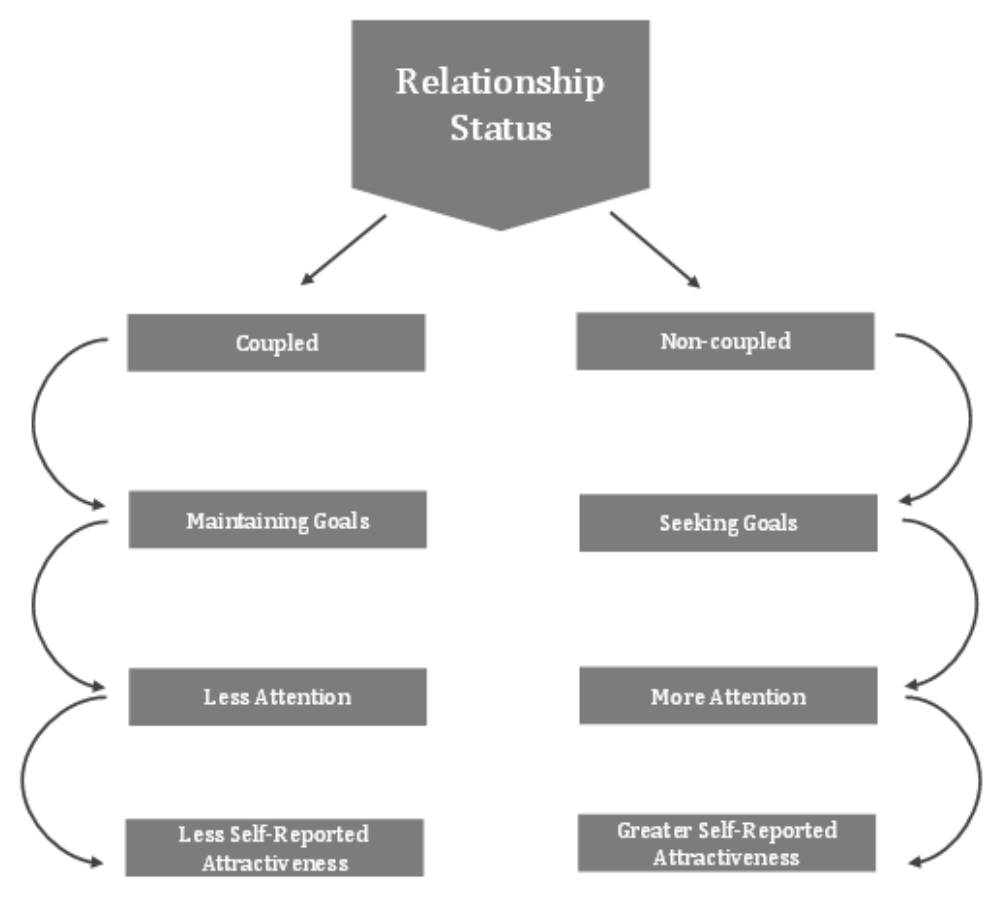

Figure 3. Goals and cognitive processes predicted to mediate the effect of relationship status on perceptions of physical attractiveness of alternative partners.

This possibility is consistent with research demonstrating that inattention is a function of relationship commitment, closeness, and feelings of love. For instance, more committed people (Miller, 1997) and people who feel more love for partners (Maner, Rouby, \& Gonzaga, 2008) spend less time looking at attractive members of the opposite sex. In the seminal study on inattentiveness, Miller (1997) found that partners who reported being more committed also reported paying less attention to alternatives. This was also found in a behavioral task in which participants browsed through a series of pictures of attractive opposite sex and same sex targets. In addition to derogating 
attractive opposite sex targets, people who were more committed also flipped through the attractive pictures more quickly than less committed people. Further, the degree to which people self-reported as inattentive also predicted relationship disillusion two months later, indicating that inattentiveness functions as a form of relationship maintenance. This makes intuitive sense, as inattention to alternatives would help to avoid any form of temptation to be lured away from one's relationship or any unfavorable comparisons. Findings suggest that when people have active relationship-seeking goals, their attention to attractive targets is heightened compared to people who do not have active relationship-seeking goal (Koranyi \& Rutherford, 2012)

\section{Conclusion}

The goal of the present study was to bridge a gap in the area of research on one particular strategy used to maintain romantic relationships; that is, devaluation of alternative partners. By comparing an involuntary measure of attractiveness to attractiveness ratings, results differentiated between the motivational hypothesis and the perceptual hypothesis. Findings suggest that when people are in a relationship they are initially attracted to alternative partners; however, they suppress or recalibrate their initial automatic perceptions of attractiveness. This research supports the idea that an intrinsic motivational mechanism is employed when people are in a relationship so as to minimize or avoid the threat of alternative partners. 


\section{REFERENCES}

Baumeister, R. F., \& Leary, M. R. (1995). The need to belong: Desire for interpersonal attachments as a fundamental human motivation. American Psychological Association, 117(3), 497-529.

Bennett, J., \& Ellison, J. (2010). 'i don't'. Newsweek, 155(25), 42-45.

Bernick, N., \& Oberlander, M. (1968) Effect of verbalization and two different modes of experiences on pupil size. Perception and Psychophysics, 3, 327-30.

Bradley, M. M., Miccoli, L., Escrig, M. A., Lang, P. J. (2008) The pupil as a measure of emotional arousal and autonomic activation. Psychophysiology, 45, 602-607.

Byrne, D., London, O., \& Reeves, K. (1968). The effects of physical attractiveness, sex, and attitude similarity on interpersonal attraction. Journal of Personality, 36(2), $259-271$

Crandall, C. S., \& Eshleman, A. (2003). A justification-suppression model of the expression and experience of prejudice. Psychological Bulletin, 129(3), 414-446.

Festinger, L. (1957). A theory of cognitive dissonance. Stanford, CA: Stanford University Press.

Gonzaga, G. C., Haselton, M. G., Smurda, J., Davies, M., \& Poore, J. C. (2008). Love, desire, and the suppression of thoughts of romantic alternatives. Evolution and Human Behavior, 29, 119-126.

Hess, E. H., \& Plot, J. M. (1960). Pupil size as related to interest value of visual stimuli. Science, 132, 349-350. 
Kenrick, D. T., \& Gutierrez, S. E. (1980). Contrast effects and judgments of physical attractiveness: When beauty becomes a social problem. Journal of Personality and Social Psychology, 38(1), 131-140.

Kenrick, D. T., Gutierrez, S. E., \& Goldberg, L. L. (1989). Influence of popular erotica on judgments of strangers and mates. Journal of Experimental Social Psychology, 25(2), 159-167.

Koranyi, N., \& Rothermund, K. (2012). When the grass on the other side of the fence doesn't matter: Reciprocal romantic interest neutralizes attentional bias towards attractive alternatives. Journal of Experimental Social Psychology, 48, 186-191.

Laeng, B., Sirois, S., \& Bredeback, G. (2012). Pupillometry: A window to the preconscious?. Perspectives on Psychological Science, 7(18), 18-27.

Lewis, C. S. (1960). Mere Christianity. (p. 92). New York: Macmillan.

Lydon, J. E., Fitzsimons, G. M., \& Naidoo, L. (2003). Devaluation versus enhancement of attractive alternatives: A critical test using the calibration paradigm. Personality and Social Psychology Bulletin, 29, 349-359.

Maner, J. K., Rouby, D., \& Gonzaga, G. C. (2008). Automatic inattention to attractive alternatives: The evolved psychology of relationship maintenance. Evolution and Human Behavior, 29, 343-349.

Martin, L. L. (1986). Set/reset use and disuse of concepts in impression formation. Journal of Personality and Social Psychology, 51, 493-504.

Miller, R. S. (1997). Inattentive and contented: Relationship commitment and attention to alternatives. Journal of Personality and Social Psychology, 73, 758-766. 
Moskowitz, G. B., Gollwitzer, P. M., Wasel, W., \& Schaal, B. (1999). Preconscious control of stereotype activation through chronic egalitarian goals. Journal of Personality and Social Psychology, 77, 167-184.

Nunnally, J. C., Knott, P. D., Duchnowski, A., \& Parker, R. (1967). Pupillary response as a general measure of activation. Perception and Psychophysics, 2, 149-55.

Petty, R. E., Briñol, P., \& DeMarree, K. G. (2007). The meta-cognitive model (mcm) of attitudes: Implications for attitude measurement, change, and strength. Social Cognition, 25(5), 657-686.

Rieger, G., \& Savin-Williams, R. C. (2012). The eyes have it: Sex and sexual orientation differences in pupil dilation patterns. PLOS ONE, 7(8).

Rusbult, C. E. (1983). A longitudinal test of the investment model: The development (and deterioration) of satisfaction and commitment in heterosexual involvements. Journal of Personality and Social Psychology, 45, 101-117.

Rusbult, C. E., \& Johnson, D. J. (1989). Resisting temptation: devaluation of alternative partners as a means of maintaining commitment in close relationships. Journal of Personality and Social Psychology, 57(6), 967-980.

Simpson, J. A., Lerma, M., \& Gangestad, S. W. (1990). Perception of physical attractiveness: Mechanisms involved in the maintenance of romantic relationships. Journal of Personality and Social Psychology, 59(6), 1192-1201.

Sinclair, L., Kunda, Z. (1999). Reactions to a black professional: Motivated inhibition and activation of conflicting stereotypes. Journal of Personality and Social Psychology, 77, 885-904. 
Thibaut, J. W., \& Kelley, H. H. (1959). The social psychology of groups. New York: Wiley.

U.S. Census Bureau. (2011, September 27). U.S. census. Retrieved from http://www.census.gov/compendia/statab/cats/births_deaths_marriages_divorces/ marriages_and_divorces.html

Wilson, T. D., Lindsey, S., \& Schooler, T. Y. (2000). A model of dual attitudes. Psychological Review, 107(1), 101-126. 
Appendix A: Consent Form

\section{Consent Form: Psychology of Advertising Study}

\section{What is the purpose of this research?}

The purpose of the Psychology of Advertising Study is to investigate college students' reactions to several advertisements. A large advertising company, in cooperation with local psychologists, is interested in how college students rate these advertisements.

\section{What will be expected of me?}

You will be asked to view and rate a series of advertisements and then provide some background information about yourself.

\section{How long will the research take?}

The study, in total, should take no longer than 30 minutes.

Will my answers be anonymous?

Yes. In no way will your name or any identifying information be linked to the data.

Can I withdraw from the study if I decide to?

Yes. You can withdraw from the research at any time and ask that your answers not be used.

Is there any harm that I might experience from taking part in the study?

There are no foreseeable risks related to the Psychology of Advertising Study.

\section{How will I benefit from taking part in the research?}

Your responses will help researchers guide prospective magazine advertisements.

\section{Who should I contact if I have questions or concerns about the research?}

Contact me (Whitney Petit) via email at wepetit1@ catamount.wcu.edu . You can also contact Dr. Leonardo Bobadilla, the Western Carolina University IRB Chair at (828) 2277212. 


\section{Do you consent to the studies above?}

Yes, I agree to participate and I understand that my participation is voluntary. I

understand that I will be able to stop participating at any point in time. I also understand that there will be no consequences for not completing the study.

No, I do not agree to participate. 
Appendix B: Example Filler Advertisement and Stimulus Advertisements

Filler Advertisement

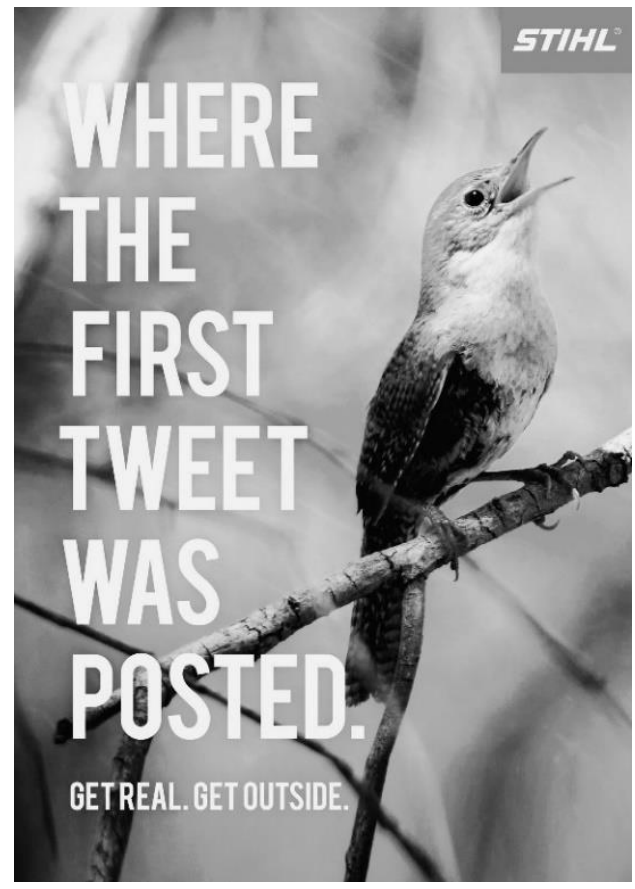

Male Stimulus Advertisement

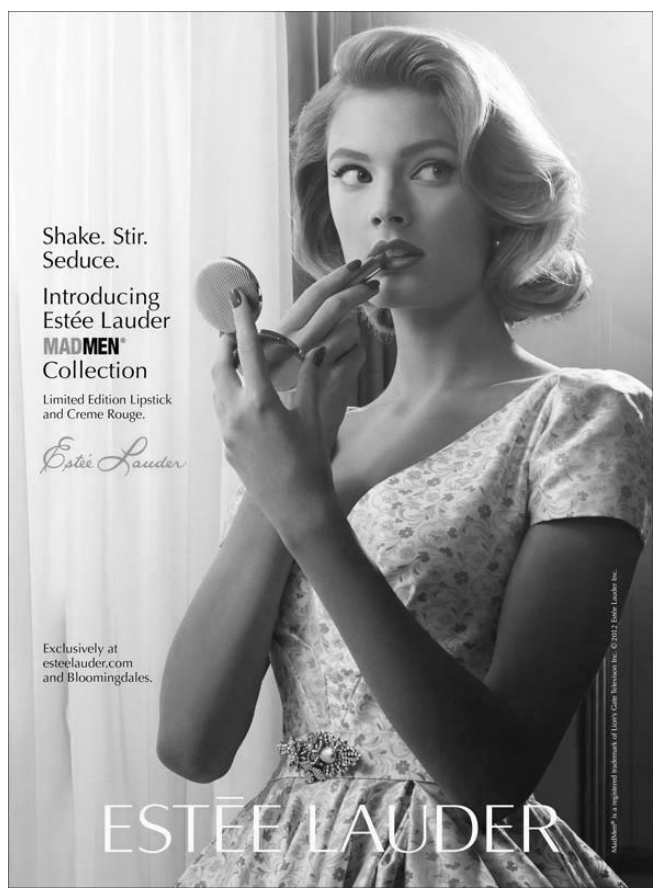


Female Stimulus Advertisement

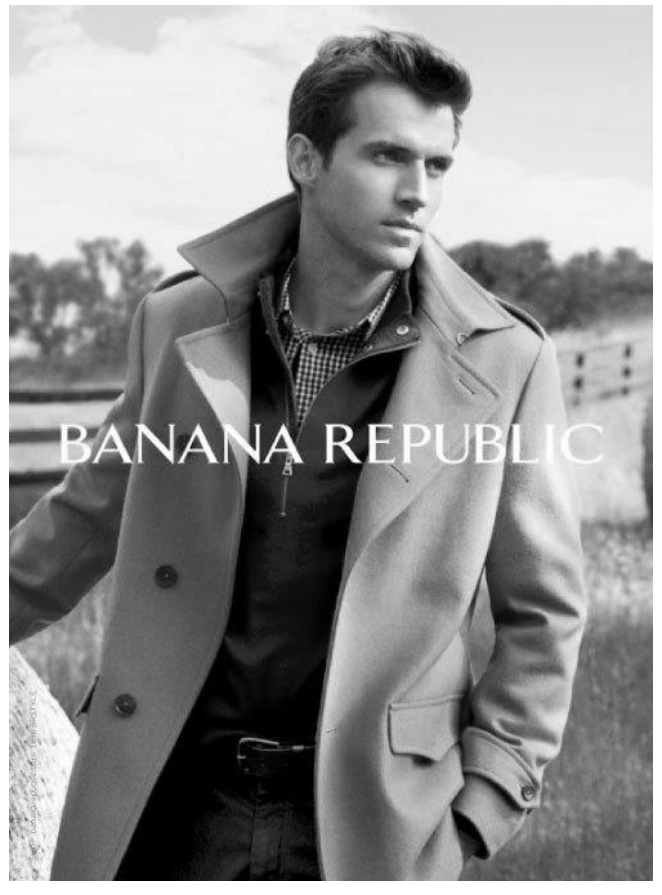




\section{Appendix C: Questionnaire for Filler and Stimulus Advertisements}

Instructions: Please indicate the degree to which you agree or disagree with the following statements as they apply to each numbered item.

Rate each advertisement according to the scale below for the following four statements.

$1=$ Strongly disagree; 2 = Moderately disagree; 3 = Slightly disagree; $4=$ Undecided 5 = Slightly

agree; 6 = Moderately agree; 7 = Strongly agree

Statements presented for each filler advertisement:

1. I like the advertisement.

2. The advertisement is persuasive.

3. The advertisement would be popular.

4. The advertisement is influential.

Statements presented for each stimulus advertisement:

1. I like the advertisement.

2. The advertisement would be persuasive.

3. The advertisement would be popular.

4. The advertisement is influential.

5. The person in the advertisement is attractive physically.

6. The person in the advertisement has sex appeal. 
Appendix D: Current Dating Status and Demographic Form

\section{Current Dating Status}

1. Are you currently dating someone?

Y Yes $\quad$ No

2. If you answered yes, how long have you been in your current relationship?

Years $\quad$ Months

3. How would you classify your sexual orientation?

_Heterosexual __ Homosexual__ Bi-sexual __ Other

4. Age 